\title{
Hochauflösende zweidimensionale Gelelektrophorese: Eine Methode für das klinisch-chemische Laboratorium
}

\author{
Von K. T. Kossmann \\ unter Mitarbeit von Claudia Lerach
}

Aus dem Labor Dr. Gärtner, Institut für medizinische Mikrobiologie und klinische Chemie, Weingarten/Württ.

(Eingegangen am 25. November 1983/13. Januar 1984)

Zusammenfassung: Arbeitsanleitungen, Reagenzien und Geräte für die Durchführung der hochauflösenden zweidimensionalen Gelelektrophorese werden beschrieben. Verkleinerung des Flachgelformats erlaubt die Durchführung beider elektrophoretischer Trennungen innerhalb eines 8-Stunden-Arbeitstages. Die Beschreibung umfaßt auch eine gut angepaßte Silberfärbung und ein Verfahren zur photographischen Dokumentation der Gele. Die Methode ist speziell für die Anwendung im klinisch-chemischen Laboratorium entwickelt worden.

\section{High resolution two dimensional gel electrophoresis: $A$ method for the clinical chemistry laboratory}

Summary: The working instructions, reagents and instruments for the performance of high resolution two dimensional gel electrophoresis are described. Size reduction of the gel slabs allows the two electrophoretic separation steps to be run within an 8-hour-working-day. The description also includes a well adapted method for silver staining and a photographic procedure for the documentation of the gels. The method is specially developed and designed for use in the clinical chemistry laboratory.

\section{Einfüihrung}

Die hochauflösende zweidimensionale Gelelektrophorese geht auf eine ausführliche Arbeit von O'Farrell (1) zurück, die bèsonders von dem Arbeitskreis um $N$. G. Anderson $(2,3,4)$ aufgegriffen, weiterentwickelt und bekannt gemacht wurde. Die Anfänge der zweidimensionalen Elektrophoresetechnik reichen in das Jahr 1968 zurück (5). Das zu trennende Eiweißggemisch wird zunächst in einem Stabgel einer isoelektrischen Fokussierung unterzogen, das dann zur Trennung in der 2. Dimension auf ein vertikales Flachgel mit linearem Vernetzungsgradienten übertragen wird. Die Trennung in der 1 . Dimension erfolgt demnach aufgrund der unterschiedlichen Oberflächenladungen der Proteine, in der 2. Dimension nach den Molekülgrößen. Der Zusatz „hochauflösend" kennzeichnet einen wichtigen Unterschied zu anderen Techniken: Die zu trennenden Proteine werden vor der Elektrophorese dissoziiert und befinden sich während der Elektrophoresen in einem Milieu, das ihre Rekonstituierung ver- hindert. Erste Versuche einer Anwendung im klinisch-chemischen Laboratorium sind inzwischen bekannt geworden $(6,7)$. Auflösungsvermögen und Reproduzierbarkeit der hochauflösenden zweidimensionalen Gelelektrophorese sind in der Tat so bestechend, daß der Einsatz dieser Technik auch in der klinisch-chemischen Forschung aussichtsreich erscheint und gefördert werden sollte.

In der vorliegenden Arbeit wird eine ausführliche Arbeitsvorschrift für die Durchführung der hochauflösenden zweidimensionalen Gelelektrophorese im klinisch-chemischen Laboratorium wiedergegeben, die es gestattet, die zwei aufeinanderfolgenden Elektrophoresen innerhalb eines 8-Stunden-Arbeitstages vorzunehmen. Die Beschreibung umfaßt ein auf die Gelformate abgestimmtes Verfahren zur Silberfärbung und eine Methode zur photographischen Dokumentation auf Röntgenfilm. Es werden Trennergebnisse gezeigt und die kritischen Punkte der Arbeitsgänge eingehend besprochen. 


\section{Material und Methoden}

Als Ampholyte wurden die Ampholine der Fa. LKB-Instrument, D-8032 Gräfelfing, mit den pH-Bereichen 3,5-10 und 2,5-4 sowie 9-11 verwendet.

Spezielle Reagenzien für die Elektrophorese wurden von der Fa. Serva, D-6900 Heidelberg, bezogen: Acrylamid p.a., N, N-Bisacrylamid reinst, Amberlite AG Typ MB-1 p.a., N,N,N,N,-Tetramethylethylendiamin (TEMED) reinst, Dodecylsulfat $\mathrm{Na}$-Salz reinst (SDS), 2-(Cyclohexylamino)ethan-2-sulfonsäure (CHES), 2-Mercaptoethanol reinst und Agarose ohne EEO reinst.

NONIDET P-40 wurde von der Fa. Sigma-Chemie, D-8028 Taufkirchen bezogen, Glutardialdehyd $25 \%$ von der Fa. Merck, D-6100 Darmstadt.

Es wurde ausschließlich demineralisiertes Wasser mit einer Leitfähigkeit von höchstens $2 \mu S$ verwendet.

Elektrophoresegeräte von der Fa. Deutsche Pharmacia, D-7800 Freiburg: 1 Gießgestell für Gelstäbe GRC-16, 1 Gießgestell für Gelkassetten GSC-8, 1 Gradientenmischer GM-1, 2 Trennkammern GE-2/4 mit Dichtungen für Flachgele $82 \times 82 \times 4,5 \mathrm{~mm}$, sowie zusätzlich 1 oberer Puffertrog mit Dichtungen für Stabgele $8 \mathrm{~mm} \varnothing, 1$ Spannungsgerät ECPS 3000/150, 1 Voltstunden-Integrator $\mathrm{VH}-1$.

Ferner wurden verwendet: 1 Mehrkanalschlauchpumpe Ismatec/ Zürich mit Technicon ${ }^{{ }}$-Schlauchsätzen $1 \times 10 \mathrm{ml} / \mathrm{min}, 1 \times 5 \mathrm{ml} /$ min, 1 Kühlthermostat SK 51 der Fa. Haake, D-1000 Berlin und 1 Spannungsgerät $2 \times 150 \mathrm{~V} / 0,5 \mathrm{~A}$ stabilisiert.

Glasplatten $82 \times 82 \times 1,5 \mathrm{~mm}$, sowie Abstandshalter aus HartPVC mit einer Dicke von $1,5 \mathrm{~mm}$ wurden am Ort beschafft. Glaskapillaren $90 \mathrm{~mm}$ lang, $8 \mathrm{~mm}$ ä.D., 1,2 $\mathrm{mm}$ i.D. fertigte die Fa. Kuglstatter, D-8046 Garching.

Zum Kleben der Gelkassetten wurde handelsübliches PVC-Isolierband $0,15 \times 19 \mathrm{~mm}$ Coroplast ${ }^{\circledR}$ verwendet.

Fotomaterial der Fa. Kodak wurde über den örtlichen Fotohandel geliefert: Kodak X-OMAT Duplicating Film $13 \times 18 \mathrm{~cm}$ Cat 1645712, Kodak GBX-Entwickler Cat 1900943, Kodak GBXFixer Cat 1901875 .

\section{Isoelektrische Fokussierung}

Das Polyacrylamidgel für die Elektrophorese in der 1. Dimension enthält folgende Bestandteile:

$\begin{array}{lc}\text { Acrylamid } & 47,5 \mathrm{~g} / \mathrm{l} \\ \text { Bisacrylamid } & 2,5 \mathrm{~g} / \mathrm{l} \\ \text { Harnstoff } & 9 \mathrm{~mol} / 1 \\ \text { Ampholine pH } 3,5-10 & 14 \mathrm{~g} / 1 \\ \text { Ampholine } \mathrm{pH} 2,5-4 & 0,8 \mathrm{~g} / 1 \\ \text { Ampholine pH } 9-11 & 2,0 \mathrm{~g} / 1 \\ \text { Nonidet P-40 } & 20 \mathrm{~g} / 1 \\ \text { TEMED } & 0,6 \mathrm{~g} / \mathrm{l} \\ \text { Ammoniumpersulfat } & 0,1 \mathrm{~g} / 1\end{array}$

Acrylamid-Harnstoff-Stammlösung

2,375 g Acrylamid, 0,125 g Bisacrylamid und $27 \mathrm{~g}$ Harnstoff werden in einem gläsernen 100 -ml-Meßzylinder mit Wasser zu einem Endvolumen von $50 \mathrm{ml}$ zur Lösung gebracht. Vollständige Lösung des Harnstoffs tritt kurz vor Erreichen der 50-ml-Marke ein. Die Lösung wird in einen 100-ml-Erlenmeyerkolben mit Schliff überführt und nach Zugabe von $0,5 \mathrm{~g}$ Amberlite 2 Stunden auf dem Magnetrührer gerührt. Im Dunkeln bei Raumtemperatur ist die Lösung 5 Tage haltbar.

\section{Gießen der Gelstäbe}

8 Glaskapillaren werden nach Anbringung einer Füllhöhenmarkierung bei $75 \mathrm{~mm}$ und dem Verschluß der unteren Offnungen mit zwei Lagen Parafilm in das Gießgestell GRC-16 eingesetzt.
Aus der Acrylamid-Stammlösung werden etwa $5 . \mathrm{ml}$ über ein Faltenfilter (S \& S 5951/2) filtriert und 4,7 ml des Filtrats in ein 25ml-Becherglas pipettiert. Weiter werden zugegeben: $175 \mu \mathrm{l}$ Ampholine pH 3,5-10, $20 \mu \mathrm{l}$ Ampholine pH 2,5-4, $50 \mu \mathrm{l}$ Ampholine pH 9-11, $100 \mu \mathrm{l}$ Nonidet P-40, $6 \mu \mathrm{l}$ einer mit Wasser 1:2 verdünnten Lösung von TEMED und $5 \mu$ leiner frisch bereiteten Lösung von Ammoniumpersulfat (100 g/l) in, Wasser. Nach sorgfältigem Mischen werden je $1000 \mu l$ des fertigen Gelgemisches in Reagenzgläser $(14 \times 85 \mathrm{~mm})$ pipettiert und je $50 \mu \mathrm{l}$ Dissoziationsgemisch (s. Probenvorbereitung) zugesetzt. Es hat sich bewährt, für jede Probe mindestens 2 Gelstäbe vorzusehen. Das Einfüllen der Gellösung in die Kapillaren erfolgt mit Hilfe einer $1000 \mu \mathrm{l}$ Eppendorf-Pipette, wobei auf die Pipettenspitze eine etwa $100 \mathrm{~mm}$ lange Teflonkapillare mit $1 \mathrm{~mm}$ Außendurchmesser aufgesetzt wird. Die durch Betätigen der Pipette vollständig mit Gel gefüllte Teflonkapillare wird bis auf den Boden der Glaskapillare geführt und dann unter fortwährender Abgabe von Gel nach oben gezogen. Der Einschluß von Luftblasen ist unbedingt zu vermeiden. Zuviel eingefülltes Gel kann im gleichen Arbeitsgang abgesaugt werden. Das Einhalten einheitlicher Füllhöhen ist wichtig. Wenn alle Kapillaren mit Gel gefüllt sind, wird mit einer Injektionsspritze mit feiner Kañüle die Geloberfläche mit Wasser überschichtet. Dabei werden die oberhalb der Füllhöhenmarkierung entstehenden Luftblasen entfernt. Bis zum Gebrauch sollten die Gelstäbe 16 Stunden bei Raumtemperatur stehen. Es empfiehlt sich daher, die Gelstäbe am späten Nachmittag zu gießen und mit Parafilm abgedeckt bis zum nächsten Morgen auspolymerisieren zu lassen.

\section{Durchführung der Elektrophorese}

Die Gelstäbe werden nach Entfernen der Parafilmverschlüsse in den oberen Puffertrog eingesetzt. Leichtes Einfetten der Silikongummidichtungen mit Silikonfett erleichtert den Einbau und schont die Dichtungen. Als Kathodenpufferlösung werden in den oberen Puffertrog $200 \mathrm{ml} 0,02 \mathrm{~mol} / \mathrm{/} \mathrm{NaOH}$ eingefüllt. Die Oberkanten der Glaskapillaren sind gleichmäßig so auszurichten, daß sie etwa $1 \mathrm{~cm}$ unter der Oberfläche des Katholyten liegen. Mit einer Injektionsspritze mit feiner Kanüle werden die noch mit Wasser gefüllten gelfreien Räume der Glaskapillaren mehrfach mit der $\mathrm{NaOH}$-Lösung gespült. In" die - Trennkammer GE-2/4 werden $3 \mathrm{I}$ einer $0,85 \mathrm{~g} / \mathrm{Phosphorsäure} \mathrm{als} \mathrm{Anolyt} \mathrm{eingefüllt} \mathrm{und}$ nach Anschluß des Spannungsgerätes zunächst 1 Stunde mit $250 \mathrm{~V}$ (konstant) und weitere 2,5 Stunden mit $500 \mathrm{~V}$ (konstant) fokussiert. Die Trennung ist nach 1500 Volt-Stunden abgeschlossen. Kühlung der Trennkammer ist wegen der geringen Leisturigsaufnahme nicht erforderlich.

\section{Auslösen und Äquilibrierung der Gelstäbe}

Nach Entnahme der Glaskapillaren aus dem Puffertrog werden die Gele unter Zuhilfenahme eines auf etwa 0,3 $\mathrm{mm}$ ausgezogenen Plastikstabes (Sarstedt 120/3), der mit Glycerin benetzt wird, vorsichtig von der Glaswand gelöst und mit einem kleinën Gummiball für Pasteurpipetten von unten nach oben in eine sogen. Badewanne ausgeblasen. Hierbei handelt es sich um selbstgefèrtigte Ausschnitte der Kanten von Reagensschachteln aus Plastik, die mit einem kleinen Standfuß versehen sind. Die Länge der Gefäße beträgt $100 \mathrm{~mm}$, das Fassungsvermögen etwa $3 \mathrm{ml}$. Ein Vorzug der Badewannen besteht vor allem darin, daß die Gelstäbe aus diesen Gefäßen ohne Zuhilfenahme weiterer Vorrichtungen in die Gelkassetten überführt werden können. In der Badewanne werden die Gelstäbe mit einem Plastikspatel gerade ausgerichtet und zweimal $5 \mathrm{~min}$ in jeweils $3 \mathrm{ml}$ Äquilibrationspuffer eingelegt, der folgende Zusammensetzung hat:

$555^{\circ} \mathrm{mg}$ Tris, $800 \mathrm{mg}$ SDS werden mit $23 \mathrm{ml}$ Wasser gelöst, mit 6 $\mathrm{mol} / \mathrm{HCl}$ auf $\mathrm{pH} 6,8$ eingestellt und $3,75 \mathrm{ml}$ Glycerin zugesetzt. Die Lösung ist täglich frisch zu bereiten.' 


\section{SDS-Gradientengelelektrophorese}

Die Trennung in der 2. Dimension erfolgt in einem SDS-haltigen, linearen Gradientengel zwischen 8,5 und 20\% Acrylamid bei einem konstanten Crosslinker-Anteil von $2,6 \%$, der eine Trennung von Polypeptiden im Molekulargewichtsbereich von etwa 10000-100000 Daiton ermöglicht.

\section{Herstellung der Gelkassetten}

Das Gelgießgestell GSC-8 nimmt 8 Gelkassetten auf, die aus den Glasscheiben und Abstandshaltern mittels PVC-Klebeband zusammengesetzt werden. Zum Aufschrumpfen des Bandes und Härten des Klebers werden die Kassetten 1 Stunde bei $60^{\circ} \mathrm{C}$ erhitzt, wodurch die Widerstandsfähigkeit gegen den SDS-Puffer erhöht wird. Zur Herstellung der schweren und der leichten Gellösung werden folgende Stammlösungen verwendet:

\section{Stammacryllösung (T 30,8\%;C 2,6\%)}

$61,6 \mathrm{~g}$ Acrylamid und $1,6 \mathrm{~g}$ Bisacrylamid werden mit Wasser auf $200 \mathrm{ml}$ gelöst. Nach Zugabe von $4 \mathrm{~g}$ Amberlite wird auf dem Magnetrührer 2 Stunden bei Raumtemperatur gerührt. Die Lösung ist im Kühlschrank 2 Wochen haltbar. Zum Gebrauch wird eine entsprechende Menge filtriert.

\section{Stammpuffer}

$-100 \mathrm{~g}$ Tris werden mit $400 \mathrm{ml}$ Wasser gelöst, mit $6 \mathrm{~mol} / \mathrm{HCl}$ auf pH 8,5 eingestellt und mit Wasser auf $500 \mathrm{ml}$ aufgefüllt.

Es werden gleiche Volumina der schweren und der leichten Lösung angesetzt. Die angegebenen Zahlen gelten für das mit $8 \mathrm{Gel}-$ kassetten besetzte Gießgestell GSC-8. Die Kassetten sind dann glatt bis zur Unterkante gefüllt, während oben ein etwa $6 \mathrm{~mm}$ hoher Leerraum bleibt, der zur Aufnahme der Gelstäbe dient.

Leichte Lösung: 13,5 ml Stammacryllösung, 13,3 ml Stammpuffer, $22,6 \mathrm{ml}$ Wasser.

Schwere Lösung: 33,0 ml Stammacryllösung, 12,3 ml Stammpuffer, 4,1 ml Glycerin.

Die Lösungen werden in 100-ml-Bechergläsern angesetzt und 20 Minuten im Vakuum mit gut wirkender Wasserstrahlpumpe entgast. Danach werden zu jedem Gefäß $500 \mu$ l SDS-Lösung (100 $\mathrm{g} /$ ) in Wasser, $28 \mu \mathrm{l}$ mit Wasser 1:2 verdünntes TEMED und 250 $\mu l$ einer frisch bereiteten wäßrigen Lösung von Ammoniumpersulfat $(100 \mathrm{~g} / \mathrm{l})$ zugesetzt.

In die Mischkammer des Gradientenmischers werden zunächst $40 \mathrm{ml}$ einer mit Bromphenolblau gefärbten Lösung von Methanol/Wasser (Volumina 1 + 4) gefüllt, die zur blasenfreien Füllung des Schlauchsystems.mit Hilfe der Pumpe bis auf einen Rest von etwa $200 \mu \mathrm{l}$ vor der Auslaßöffnung der Mischkammer in das Schlauchsystem und das Gelgießgestell gepumpt werden. Das Schlauchsystem zur Förderung des Gradientengels hat eine Förderleistung von $10 \mathrm{ml} / \mathrm{min}$. Ein zweites Schlauchsystem zur Förderung der schweren Gellösung in die Mischkammer hat eine Förderleistung von $5 \mathrm{ml} / \mathrm{min}$. Durch Pumpen im Kreis, von und zum Vorratsgefäß der schweren Gellösung wird dieses Schlauchsystem gleichzeitig mit dem Einfüllen der Methanol/Wasserlösung blasenfrei gemacht. Nach dem Einfüllen der leichten Gellösung in die Mischkammer wird der Ablaufschlauch der schweren Gellösung in die Mischkammer gehängt, Pumpe und Mischer eingeschaltet und der Gelgradient in die Kassetten gefördert. Wenn die Gellösung aus der Mischkammer bis auf einen Rest von etwa 200 $\mu l$ vor der Auslaßöffnung abgepumpt ist, wird die Pumpe kurz abgeschaltet und $40 \mathrm{ml}$ einer mit Bromphenolblau gefärbten Lösung aus Glycerin und Wasser (Volumina, $1+1$ ) in die Mischkammer gegeben. Mit Hilfe dieser Lösung wird das im Schlauchsystem und unteren Totraum des Gelgießgestells enthaltene Gradientengel nach Wicdereinschalten der Pumpe in die Gelkasset- ten gefördert. Die Pumpe wird abgeschaltet, wenn die blaue Glycerinlösung die Unterkanten der Gelkassetten im Gießgestell erreicht hat. Das Gelgießgestell wird mit einer Schlauchklemme verschlossen und die Schlauchsysteme werden sofort mit reichlich Wasser gespült.

Die Gelkassetten sind nach etwa 2 Stunden polymerisiert. Sie werden aus dem Gießgestell herausgenommen und unter fließendem, kalten Leitungswasser von außen anhaftendem Polyacrylamid befreit. Eventuell überstehende Gelkanten an der Unterseite der Kassetten können mit einem scharfen Messer abgeschnitten werden. Die fertigen Gelkassetten werden in einer feuchten Kammer im Kühlschrank gelagert.

\section{Durchführung der Elektrophorese}

Während die Gelstäbe im Äquilibrationspuffer liegen, werden die Gelkassetten durch einen 10 min dauernden Elektrophoresevorlauf äquilibriert. Als Kammerpuffer dient eine Lösung aus:

9,393 g Tris, 44,135 g Glycin und 3,1 g SDS gelöst auf 3,11 Wasser.

Der Einbau der Gelstäbe wird an den im Puffertrog eingesetzten, passend hochgeschobenen Gelkassetten vorgenommen. Der Äquilibrationspuffer wird aus den Badewannen abgesaugt und die Gelstäbe werden unter Zuhilfenahme eines Plastikspatels über die lange Kante der Badewanne in den Schlitz der Gelkassette gerollt. Eventuell auftretende Luftblasen zwischen Gelstab und Gradientengeloberfläche werden durch leichtes Andrücken des Gelstabs mit dem Plastikspatel entfernt. Abschließend werden die Gelkassetten durch Zugabe heißer, mit Kammerpuffer hergestellter Agaroselösung $(10 \mathrm{~g} / \mathrm{l})$ aufgefüllt und die Gelstäbe dadurch fixiert. Der Agarose werden einige Tropfen Bromphenolblaulösung als Marker zugesetzt. Der obere Puffertrog wird in die Trennkammer eingesetzt und mit Kammerpuffer gefüllt. Die Oberkanten der Gelkassetten müssen waagerecht so ausgerichtet sein, daß sie wenigstens $1 \mathrm{~cm}$ unter der Pufferoberfläche liegen. Ohne Pufferumwälzung zwischen Obertrog und unterer Pufferkammer wird die Elektrophorese bei $150 \mathrm{~V}$ (konstant) solange betrieben, bis das Bromphenolblau als schmales Band in das Polyacrylamidgel eingedrungen ist. Danach wird die Pufferumwälzung eingeschaltet und die Elektrophorese bei $150 \mathrm{~V}$ fortgesetzt. 30 Minuten nach dem Austritt des Markerfarbstoffes aus der unteren Gelkassettenöffnung ist die Trennung vollständig. Das entspricht einer Gesamtlaufzeit von 3 Stunden. Die hohe Leistungsaufnahme von zeitweilig $30 \mathrm{~W}$ macht den Anschluß der Trennkammer an einen Kühlthermostaten mit Umwälzpumpe erforderlich. Der Kammerpuffer unterliegt einer starken Elektrolyse und muß nach einmaligem Gebrauch verworfen werden.

\section{Probenvorbereitung}

Zur Dissoziation der Proteine im Untersuchungsmaterial wird folgender Dissoziationspuffer verwendet:

$100 \mathrm{mg}$ CHES, $200 \mathrm{mg}$ SDS, $10 \mathrm{mg}$ Glycin werden in $7,5 \mathrm{ml}$ Wasser gelöst, mit $2 \mathrm{ml}$ Glycerin versetzt und mit $1 \mathrm{~mol} / 1 \mathrm{NaOH}$ auf pH 9,5 eingestellt.

Zu $90 \mu$ Dissoziationspuffer in einem Eppendorf-Reaktionsgefä $\beta$ werden $5 \mu$ l Serum und $5 \mu$ leiner mit Dissoziationspuffer $1: 5$ verdünnten Mercaptoethanollösung zugegeben. Der Ansatz wird für 5 Minuten in ein $95^{\circ} \mathrm{C}$ Wasserbad gestellt, anschließend abgekühlt und bis zur Verwendung im Kühlschrank aufbewahrt (s. Gießen der Gelstäbe).

\section{Fixierung und Silberfärbung der Flachgele}

Nach Beendigung der Gradientengelelektrophorese werden die Kassetten durch Abziehen der Klebcbänder geöffnet und die Gele, ohne sie mit den Fingern zu berühren, in Petrischalen aus Glas (200 mm $\varnothing, 45 \mathrm{~mm}$ hoch) gelegt. Jedes Gel erhält eine cigenc 


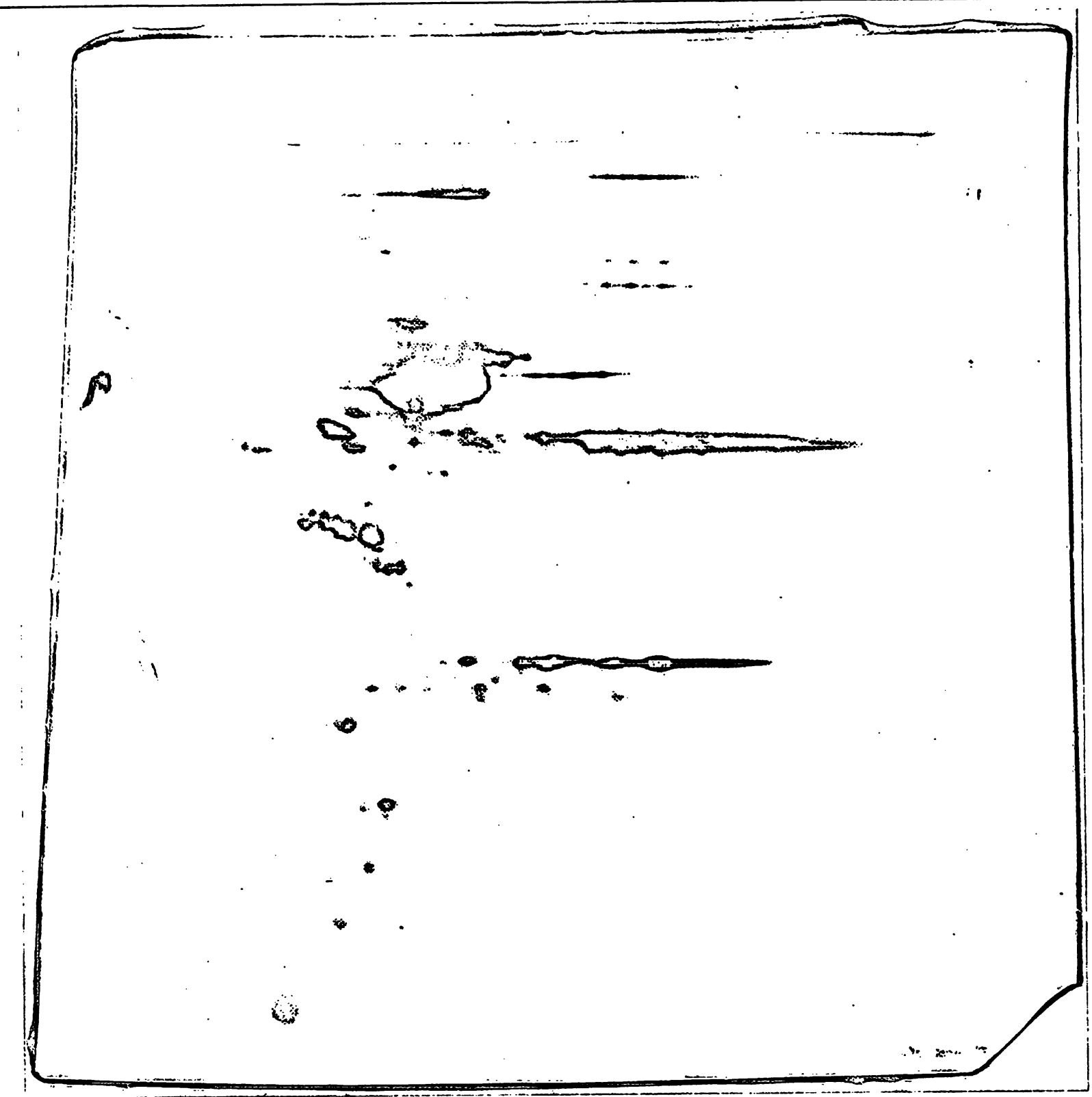

Abb. 1. Proteinmuster des Serums eines Patienten mit monoklonaler Gammopathie (IgG).

a) Originalphotogramm, etwa 1,5 -fach vergrößert

Petrischale, in der es über alle Stufen der Fixierung und Färbung bleibt. Der Wechsel von Fixier-, Wasch- und Färbelösung erfolgt durch Absaugen mit einer Wasserstrahlpumpe.

Die Gele werden zunächst für 1 Stunde in eine Lösung aus Methanol/Wasser/Eisessig (Volumina $45+45+10$ ) gelegt und auf einem Horinzontalschüttler leicht geschüttelt. Nach diesem Fixierbad werden die Gele dreimal mit jeweils $200 \mathrm{ml}$ Wasser gespült und über Nacht in einer wäßrigen Lösung von Glutardialdehyd $(10 \mathrm{~g} / \mathrm{l})$ stehen gelassen. Am folgenden Morgen werden die Gele dreimal mit jeweils $200 \mathrm{ml}$ Wasser gewaschen und für etwa 3 Stunden in Wasser stehen gelassen. Vor der Silberfärbung werden die Gele nochmals kurz in frischem Wasser gespült und dann für 30 Minuten unter leichtem Schütteln in eine Silberfärbelösung folgender Zusammensetzung gelegt:
In einem gläsernen 100-ml-Meßzylinder werden zu $40 \mathrm{ml}$ Wasser $1 \mathrm{ml} 1 \mathrm{~mol} / \mathrm{NaOH}, 1 \mathrm{ml}$ Ammoniaklösung $(250 \mathrm{~g} / 1)$ und tropfenweise unter Schütteln $1 \mathrm{ml}$ Silbernitratlösung $(200 \mathrm{~g} / \mathrm{l})$ gemischt und mit Wasser auf $100 \mathrm{ml}$ aufgefüllt.

Die Silberlösung wird nach Gebrauch in eine gesonderte Vorlage abgesaugt und zur Silberrüickgewinnung mit Salzsäure versetzt. Das Gel wird einmal mit $200 \mathrm{ml}$ Wasser gewaschen und nochmals für 30 Minuten in Wasser gelegt. Nach Absaugen, dieses Wassers werden $120 \mathrm{ml}$ Wasser und $200 \mu \mathrm{l}$ Entwickler zu dem Gel in die Schale gegeben. Der Entwickler wird täglich frisch bereitet aus $40 \mathrm{mg}$ Zitronensäure, $2 \mathrm{ml}$ Wasser und $100 \mu \mathrm{l}$ Formaldehydlösung $(370 \mathrm{~g} / 1)$. Die Entwicklung verläuft auf dem Schüttler in etwa 30 Minuten. Auch nach dem Absaugen der Entwicklerlösung und mehrfachem Waschen der Gele verștärrkt sich die Färbung noch weiter. 


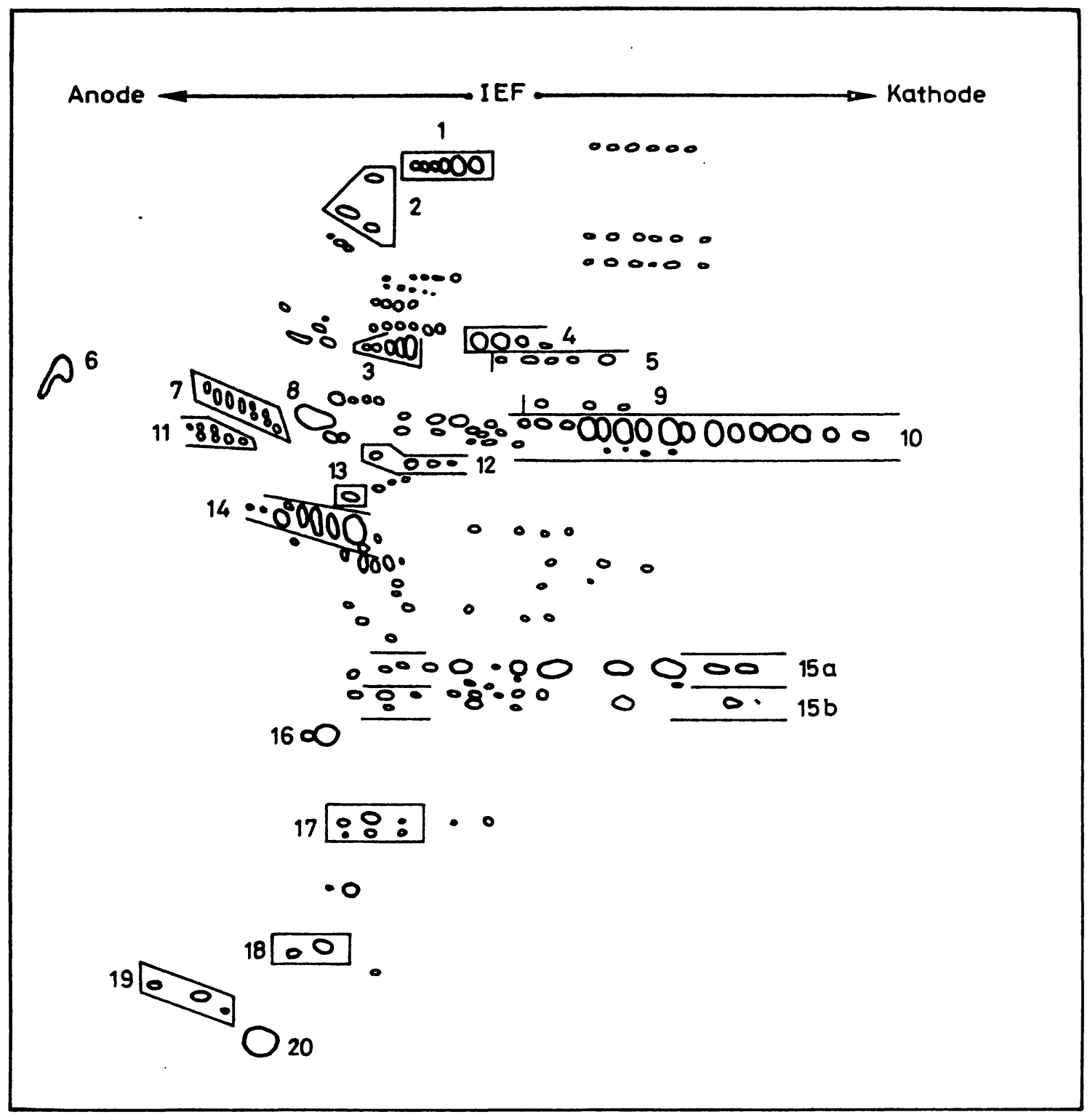

Abb. 1. Proteinmuster des Serums eines Patienten mit monoklonaler Gammopathie (IgG).

b) Schematisierte Darstellung

Molekulargewichtsgradient: $10^{5}$ Dalton oben, $10^{4}$ Dalton unten. Albumin ist nicht eingezeichnet. Die identifizierbaren Proteine

(2) sind mit Ziffern versehen:

$1 \alpha_{2}$-Makroglobulin

2 Coeruloplasmin

3 Hämopexin

4 Transferrin

5 Fibrinogen, $\alpha$-Kette
6 saures $\alpha_{1}$-Glykoprotein

$7 \alpha_{1}$-Antichymotrypsin

$8 \alpha_{1}$-Antitrypsin

9 Fibrinogen, $\beta$-Kette

10 IgG, schwere Ketten
$11 \alpha_{2}$-HS Glykoprotein

12 Fibrinogen, $\gamma$-Kette

13 Thrombocyten-Actin

14 Haptoglobin, $\beta$-Kette

15 Immunglobulin

a Leichtketten Typ $\lambda$

b Leichtketten Typ $x$
16 Apolipoprotein A-1

17 Haptoglobin, $\alpha-$ Kette

18 Präalbumin

19 LDL-Lipoproteine

20 Apolipoprotein A-2

\section{Photodokumentation}

Die Arbeiten müssen in einer Dunkelkammer bei schwạchem Rotlicht vorgenommen werden. Auf einer glatten Unterlage werden der Film, darauf eine saubere Klarsichtfolie und darauf ohne Einschluß von Luftblasen das Flachgel geschichtet. Darüber wird im Abstand von $15 \mathrm{~cm}$ eine UV-Lampe mit Strahlung bei $366 \mathrm{~nm}$ angebracht. Da die Lampe mit Flackerlicht geringer Energie zündet, wird zur Erzielung einer reproduzierbaren Belichtung das Flachgel mit einem $20 \times 20 \mathrm{~cm}$ großen Stück Fotokarton solange abgedeckt, bis die Lampe gezündet hat. Als Richtwert der Belichtungszeit gelten 10 Sekunden. Für die Entwicklung und Fixierung des Films werden jeweils 4 Minuten benötigt. Der Filmpackung liegt eine Entwicklungsvorschrift bei.

\section{Reinigen der Glasgeräte}

Da die Polymerisation von Acrylamid durch Verunreinigungen auf den von Natuŕ sehr adsorptionsfreudigen Glasflächen erheblich beeinträchtigt werden kann, ist bei der Reinigung große Sorgfalt anzuwenden. Die Glasscheiben der Gelkassetten werden für einige Stunden in Extran ${ }^{\otimes}(50 \mathrm{~g} / 1)$ eingelegt, danach gründlich gewässert und gespült und im Heißluftschrank getrocknet. Die Glaskapillaren werden in Salpetersäure $(200 \mathrm{~g} / \mathrm{l})$ gelegt und während des mehrstündigen Verweilens zwischendurch 15 Minuten im UItraschallbad behandelt. Nach einer Spülung mit Wasser werden die Kapillaren in eine Kaliumcarbonatlösung (100 g/) gelegt, abschließend an der Wasserstrahlpumpe mit reichlich Wasser gespült und im Heißluftschrank getrocknet. 


\section{Ergebnisse und Diskussion}

Die hohe Trennleistung des Verfahrens wird in Abbildung 1 veranschaulicht. Es handelt sich um das Serum eines Patienten mit einem IgG-Immunocytom. Abbildung $1 \mathrm{~b}$ ist eine schematisierte Darstellung der Abbildung 1a, in der die identifizierbaren Proteine in Anlehnung an einen Standard von $A n-$ derson (2) gekennzeichnet sind. Die Legende enthält die zugehörigen Erläuterungen. Die Wiedergabe der Trennung eines pathologisch veränderten Serums in Abbildung 1 gibt Gelegenheit, auf einige Besonderheiten hinzuweisen. Bei der isoelektrischen Fokussierung von Serum bereitet die Auftrennung der basischen Proteine, insbesondere der Immunglobuline $\mathrm{G}$, Schwierigkeiten. Wie die Abbildung 1 zeigt, ist durch das Zumischen der zu trennenden Proteine zum unpolymerisierten Gel vor dem Gießen der Gelstäbe eine annehmbare Trennung der Schwerund Leichtkettenklone erzielt worden. Die pathologische Veränderung besteht in einer mächtigen Verdichtung einzelner Klone bzw. Proteinflecken im Bereich der schweren IgG-Ketten und vor allem im Bereich der Leichtketten. Ein weiteres Problem bei der Auftrennung von Serum mittels der hochauflösenden zweidimensionalen Gelelektrophorese ergibt sich aus der Tatsache, daß die Konzentrationen der einzelnen Proteinspezies eine Spanne von einigen Zehnerpotenzen umfassen. Eine mäßig empfindliche Proteinfärbung, wie die Coomassie-Blau-Färbung bringt daher gewissermaßen nur den Vordergrund des mit einem Sternenhimmel vergleichbaren Proteinmusters zur Darstellung. Die empfindlichere Silberfärbung dringt zwar viel weiter in die Tiefe, wird aber bei sehr weitgehender Entwicklung in hohem Maße von den hochkonzentrierten Proteinen ,überstrahlt " ". Neben diesem färberischen Problem gibt es bei Serumtrennungen, bedingt durch die unterschiedlich hohen Proteinkonzentrationen auch eine Überladung der Stabgele bei der isoelektrischen Fokussierung, die eine ungenügende Trennung zur Folge hat. Um eine gute Darstellung der Schwer-und Leichtkettenklone in den Seren von Immunocytompatienten zu erzielen, führen wir regelmäßig eine Verdünnung des Serums auf eine IgG-Konzentration von $10 \mathrm{~g} / \mathrm{l}$ durch. Das führte im vorliegenden Fall auch zu einer vorzüglichen Auftrennung der sauren Glykoproteine, vor allem von $\alpha_{1}$-Antichymotrypsin und $\alpha_{2}-\mathrm{HS}$ Glykoprotein. In Abhängigkeit von der Fragestellung kann es also durchaus notwendig sein, durch Serumverdünnung oder den Eintrag von weniger Serum bei der Probenvorbereitung dem Problem der Úberladung vorzubeugen. In diesem Zusammenhang sei auch erwähnt, daß es aussichtsreiche Versuche gibt, die „vordergründigen“
Serumproteine aus dem Bild zu entfernen und in die Tiefe, zu den geringer konzentrierten und weniger bekannten Proteinen vorzudringen $(8,9)$.

In Abbildung 2 ist der in proteinfreien Gelstäben nach 1500 Volt-Stunden erzeugte pH-Gradient dargestellt. Zur Messung wurden die Gelstäbe nach isoelektrischer Fokussierung in $5 \mathrm{~mm}$ lange Stücke aufgeschnitten und jeweils identische Stücke aus 4 Gelstäben mit $1 \mathrm{ml} \mathrm{CO}$-freiem Wasser für 2 Stunden bei Raumtemperatur eluiert. Im Eluat wurde der $\mathrm{pH}$-Wert mit einer Mikro-Einstabelektrode (Ingold U $402 \mathrm{M} 8$ ) gemessen.

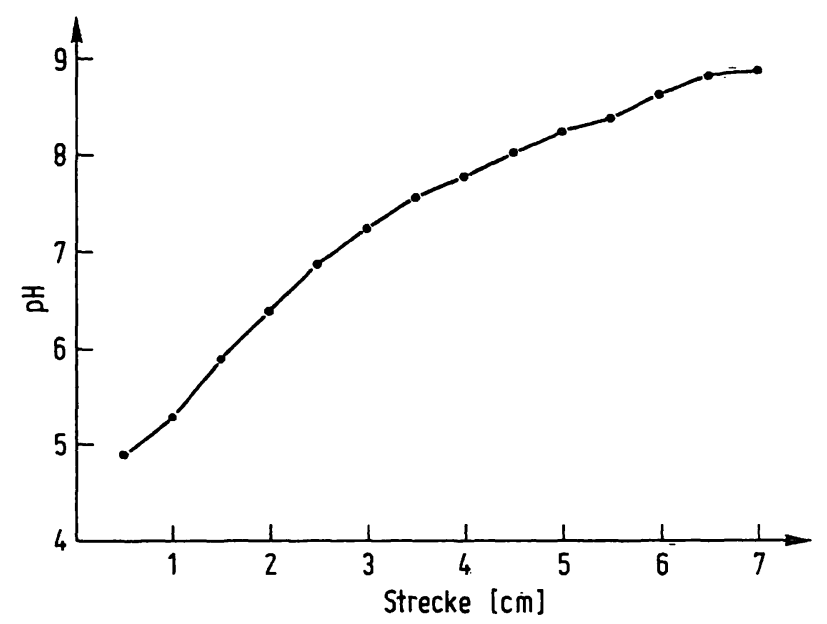

Abb. 2. pH-Gradient der isoelektrischen Fokussierung.

Die vorliegende ausführliche Methodenbeschreibung stellt einen Erfahrungsbericht über eine nun 18 Monate dauernde Erprobung und Weiterentwicklung bekannter Arbeitsanleitungen zur hochauflösenden zweidimensionalen Gelelektrophorese dar $(1-4,6,10,11)$. Die Verkleinerung der Gelfläche auf ein Fünftel des üblichen Formats von $180 \times$ $200 \mathrm{~mm}$ führte zu einer beträchtlichen Verkürzung der elektrophoretischen Trennzeiten, so daß diese Arbeitsgänge nun innerhalb eines 8-Stunden-Arbeitstages leicht durchgeführt werden können. Die Verringerung des Reagenzienverbrauchs ist ein zusätzlicher Vorteil. Auflösung und Klarheit der Darstellung in dem kleineren Gelformat stehen demjenigen in großflächigen Gelen nicht nach. Die Reduzierung der Geldicke von 2,7 auf 1,5 mm lieferte eine wichtige Voraussetzung für die wirksame Anwendung der hochempfindlichen Silberfärbung, die überdies auch durch die bessere Hantierbarkeit der kleinflächigen Gele erleichtert wird.

Die Herstellung der Gradientengele erfordert eine zweckentsprechende Vorrichtung, die mit dem Gradientenmischer GM-1, der Mehrfaçhischlauchpumpe und dem Gelgießgestell GSC-8 in einfacher Form 
gegeben sind. Turbulenzen im Schlauchsystem beeinträchtigen die Präzision der Gradientenformung. Der Gelstrom soll daher aufwärts gerichtet sein, d.h. das Gießgestell muß höher stehen als der Pumpentisch und dieser wiederum höher als der Gradientenmischer. Vorteilhaft ist auch die Zuführung der schweren Gellösung in die Mischkammer mit Hilfe aktiver Förderung durch die Pumpe, anstelle der beim Gradientenmischer vorgesehenen Zufuhr durch das kommunizierende Gefäßsystem.

Bei der Auswahl eines Spannungsgerätes ist zu beachten, daß beide Elektrophoresen mit konstanter Spannung betrieben werden. Für die isoelektrische Fokussierung bedeutet dies Leistungsdaten des Spannungsgerätes von $500 \mathrm{~V}$ und $10 \mathrm{~mA}$ für 20 Stabgele. Dagegen wird für die Gradientengelelektrophorese ein Gerät mit hoher Leistungsabgabe benötigt. Hier geht bei einer Spannung von nur $150 \mathrm{~V}$ zeitweilig ein Strom von $250 \mathrm{~mA}$ durch vier Flachgele in einer Trennkammer. Beim Betrieb von 2 Trennkammern mit 8 Flachgelen wird mithin eine Stromfestigkeit von $500 \mathrm{~mA}$ benötigt. Die Verwendung eines Voltstundenintegrators bei der isoelektrischen Fokussierung ist nützlich. Für die Kühlung der Flachgelelektrophorese ist ein Kühlthermostat hinreichender Leistung erforderlich. Die abzuführende Wärmeleistung bei 8 Flachgelen liegt bei $60 \mathrm{~W}$.

Die Silberfärbung geht teilweise auf Angaben von Porro et al. (10) zurück. Silberionen haben eine hohe Affinität zu Aminosäuren, Peptiden und Proteinen. Ihre Reduktion zu metallischem Silber kann grundsätzlich im Augenblick der Bindung, durch chemische Entwickler und auch durch Belichtung erfolgen. Neben den nachzuweisenden Proteinen enthalten die Gele infolge der elektrochemischen Prozesse während der Elektrophoresen eine große Zahl undefinierter aber hochaktiver Verbindungen in hohen Konzentrationen, die sich teilweise mit der Polyacrylmatrix verbinden. Diese verursachen nach der Silberfärbung eine starke Schwärzung, die bis zur vollständigen Versilberung der Gele führen kann. Ausgiebiges Waschen der Gele nach hinreichender Fixierung der nachzuweisenden Proteine ist daher oberster Grundsatz bei der Anwendung der Silberfärbung. Eine kräftige Verstärkung der Silberanlagerung an alle affinen Bestandteile der Gele wird durch die Behandlung mit Glutardialdehyd erzielt. Wie die meisten Aldehyde neigt auch diese Verbindung zur spontanen Polymerisation durch Aldolkondensation. Es ist daher nicht möglich, Glutardialdehydlösungen definierter Wirksamkeit für die Silberfärbung $\mathrm{zu}$ beschaffen oder herzustellen. Daher kann es notwendig sein, die Konzentration der Lösung auf $20 \mathrm{~g} /$, maximal $40 \mathrm{~g} / \mathrm{zu}$ erhöhen.
Das Absorptionsmaximum der gelben Grundtönung der silbergefärbten Gele liegt bei $340 \mathrm{~nm}$. Bei Dokumentation auf Farb-Diafilm wird durch Verwendung eines Blaufilters ein höherer Kontrast erreicht. Die Dokumentation auf Kodak X-OMAT Kopierfilm geht auf eine Mitteilung von Harrison (11) zurück. Der positiv abbildende Film ist UV-empfindlich und liefert nur bei Belichtung mit UV-Licht scharfe Kontaktabzüge. Als Lichtquelle können Schwarzlichtlampen oder UV-Lampen verwendet werden. Das einfach durchführbare Verfahren bietet entscheidende Vorteile. Die vom menschlichen Auge schwer abstufbaren Gelb-Braun-Schwarztöne der Silberfärbung werden in harte Grau-Schwarztöne umgesetzt, die als schärferes Bild mit höherer Auflösung wahrgenommen werden, d.h. auf dem Photogramm werden Proteinflecken sichtbar, die auf dem gefärbten Gel mit bloßem Auge nicht zu erkennen sind.

Die diagnostische Beurteilung der Trennergebnisse der hochauflösenden zweidimensionalen Gelelektrophorese wird wahrscheinlich noch längere Zeit ein subjektives Verfahren bleiben, da die rechnergestützte Bildauswertung noch am Anfang ihrer Entwicklung steht. Es gelingt jedoch in kurzer Zeit, sich in die Bilder "einzusehen" und charakteristische Merkmale oder bestimmte Veränderungen rasch wahrzunehmen. Insoweit besteht eine gewisse Ubereinstimmung mit der Auswertung von Röntgenbildern.

Durch Unterlegen eines transparenten Millimeterrasters unter den Film können die Koordinaten einzelner markanter Proteine leicht ausgemessen werden. Dabei kann das Apolipoprotein A-1 wegen seiner isolierten und außerordentlich konstanten Lage im linken unteren Bildquadranten als KoordinatenNullpunkt benutzt werden. Dieses Verfahren eignet sich vorzüglich zur Úberprüfung der Reproduzierbarkeit und Präzision. So ergab die Vermessung von 25 Photogrammen für den horizontalen Abstand zwischen $\alpha_{1}$-Antitrypsin und Transferrin einen $\mathrm{Va}$ riationskoeffizienten der isoelektrischen Fokussierung von $\pm 6,47 \%$ und des vertikalen Abstands zwischen Apolipoprotein A-1 und Transferrin einen Variationskoeffizienten der Gradientengelelektrophorese von $\pm 2,38 \%$. Unter Berücksichtigung der Tatsache, daß das Auflösungsvermögen des Meßverfahrens nur bis etwa $0,5 \mathrm{~mm}$ reicht, spiegeln diese Werte die außerordentlich hohe Reproduzierbarkeit und Präzision der hochauflösenden zweidimensionalen Gelelektrophorese auch in der hier beschriebenen Methodik im stark verkleinerten Maßstab überzeugend wieder. In unserem Institut ist die Durchführung der hochauflösenden zweidimensionalen Gelelektrophorese als Standardmethode fest eingeführt. Es werden täglich 8 Einzelelektrophoresen fertiggestellt. 


\section{Literatur}

1. O'Farrell, P. H. (1975) J. Biol. Chem. 250, 4007-4021.

2. Anderson, N. L. \& Anderson, N. G. (1977) Proc. Natl. Acad. Sci. (Wash.) 74, 5421-5425.

3. Anderson, N. G. \& Anderson, N. L. (1978) Anal. Biochem. $85,331-340$.

4. Anderson, N. L. \& Anderson, N. G. (1978) Anal. Biochem. 85, 341-354.

5. Klose, J., Nowak, J. \& Kade, W. (1980) Electrophoresis '79 (Radola, B. J., ed.) Verlag Walter de Gruyter, Berlin, New York, pp. 297-312.

6. Tracy, R. P., Currie, R. M., Kyle, R. A. \& Young, D. S. (1982) Clin. Chem. 28, 900-907.

7. Jellum, E. \& Thorsrud, A. K. (1982) Clin. Chem. 28, 876883.

8. Allen, R. C., Arnaud, P., Sammons, D. W. \& Adams, L. D. (1983) Elektrophorese Forum '83, 4. Diskussionstagung München, 24.-26. Oktober 1983 (Radola, B. J., ed.) pp. 30-39.

9. Kossmann, K. T. (1983) Eur. J. Cell Biol., Suppl. 4, 11.

10. Porro, M., Viti, S., Antoni, G. \& Saletti, M. (1982) Anal. Biochem. 127, 316-321.

11. Harrison, H. H. (1983) Clin. Chem. 29, 1566-1567.

\section{Anfügung bei der Fahnenkorrektur}

Während der Drucklegung dieser Arbeit erschien in dieser Zeitschrift eine Veröffentlichung über zweidimensionale Elektrophorese aus dem Arbeitskreis von Gabl (diese Z. 22, 53-59, 1984). Es handelt sich bei der beschriebenen Methode um die sogen. horizontale Flachbett-Technik, die als Alternative zur hier beschriebenen vertikalen Technik nach $O^{\prime}$ Farrell angesehen werden kann. Das zufällige und rasche Aufeinanderfolgen zweier Veröffentlichungen zum gleichen Thema gibt dem Leser die begrüßenswerte Möglichkeit zum Vergleich der beiden vorgestellten Methoden. 